\title{
Tribological Study on Tailored-Formed Axial Bearing Washers
}

\author{
Florian Pape ${ }^{1)^{*}}$, Timm Coors ${ }^{1)}$, Alexander Barroi ${ }^{2)}$, Jörg Hermsdorf ${ }^{2}$, Maximilian Mildebrath ${ }^{3)}$, \\ Thomas Hassel ${ }^{3)}$, Stefan Kaierle ${ }^{2)}$, Tim Matthias ${ }^{4)}$, Alexander Chugreev ${ }^{4}$, Anna Chugreeva ${ }^{4)}$, \\ Bernd-Arno Behrens ${ }^{4}$, Ludger Overmeyer ${ }^{2}$ and Gerhard Poll ${ }^{1)}$ \\ ${ }^{1)}$ Institute of Machine Design and Tribology (IMKT), Leibniz Universitaet Hannover, 30167, Hannover, Germany \\ ${ }^{2)}$ Laser Zentrum Hannover e.V. (LZH), 30419, Hannover, Germany \\ ${ }^{3)}$ Institute of Material Science (IW), Leibniz Universitaet Hannover, 30823, Garbsen, Germany \\ ${ }^{4)}$ Institute of Forming Technology and Machines (IFUM), Leibniz Universitaet Hannover, 30823, Garbsen, Germany \\ *Corresponding author: Florian Pape (pape@imkt.uni-hannover.de)
}

Manuscript received 31 January 2018; accepted 31 August 2018; published 31 December 2018

Presented at the 6th World Tribology Congress 2017 Beijing, September 2017

\begin{abstract}
To enhance tribological contacts under cyclic load, high performance materials are required. Utilizing the same high-strength material for the whole machine element is not resource-efficient. In order to manufacture machine elements with extended functionality and specific properties, a combination of different materials can be used in a single component for a more efficient material utilization. By combining different joining techniques with subsequent forming, multi-material or tailored components can be manufactured. To reduce material costs and energy consumption during the component service life, a less expensive lightweight material should be used for regions remote from the highly stressed zones. The scope is not only to obtain the desired shape and dimensions for the finishing process, but also to improve properties like the bond strength between different materials and the microscopic structure of the material. The multi-material approach can be applied to all components requiring different properties in separate component regions such as shafts, bearings or bushes. The current study exemplarily presents the process route for the production of an axial bearing washer by means of tailored forming technology. The bearing washers were chosen to fit axial roller bearings (type 81212). The manufacturing process starts with the laser wire cladding of a hard facing made of martensitic chromium silicon steel (1.4718) on a base substrate of S235 (1.0038) steel. Subsequently, the bearing washers are forged. After finishing, the surfaces of the bearing washers were tested in thrust bearings on an FE-8 test rig. The operational test of the bearings consists in a run-in phase at $250 \mathrm{rpm}$. A bearing failure is determined by a condition monitoring system. Before and after this, the bearings were inspected by optical and ultrasonic microscopy in order to examine whether the bond of the coat is resistant against rolling contact fatigue. The feasibility of the approach could be proven by endurance test. The joining zone was able to withstand the rolling contact stresses and the bearing failed due to material-induced fatigue with high cycle stability.
\end{abstract}

\section{Keywords}

tailored forming, axial bearing washers, bearing fatigue life

\section{Introduction}

Tribological contacts under cyclic load, such as rolling contacts, require high performance materials in order to resist the induced stresses. Conventional components made of a single material converge to their material-specific limits and are not resource-efficient. In contrast to mono-material components, multi-material design offers ample potential for producing components with an extended functionality, higher durability and specific properties optimized according to a particular application area. By using lower strength and less expensive materials in less critically loaded zones, material costs and energy consumption can be reduced [1]. For contact zones exposed to higher stresses, a wear-resistant material with higher fatigue strength (e. g. high-strength steel) can be used [2]. The underlying substrate can be made of low-priced steel or aluminum. Special focus has to be set on the joining zone where no pores or impurities should weaken functionality. A delamination of the coating has to be avoided. Joining of the two different materials can be realized, for example, by laser cladding. This approach was described in 1998 by Hetzner as a future possibility of enhancing bearing properties [3]. Enomoto 
and Yamamoto emphasize laser cladding as a tool to enhance the local properties of tribomaterials in the automotive sector [4]. The possibility of laser cladding for manufacturing coatings applied as bearing surfaces was presented previously by Torims as well as Pape et al. [5, 6]. Weisheit et al. recommend Co-based alloys claddings used for the wear protection of diesel engine parts and bearings [7].

The aim of this study is to adopt specific materials to the locally required demands in one component. This can be achieved by first joining them using the aforementioned process and then forming them together. Forging offers the benefit of pore reduction and improved surface texture with smaller grains [8]. For this, not only the desired shape and dimensions after the finishing process, but also properties such as bond strength between the different materials and material structures should be obtained. This specific approach of tailored-formed parts can be applied to machine elements such as shafts [8], bearings [9], or bushings [10]. In this study, hybrid bearing washers have been manufactured through tailored forming. The bearing washers were chosen to fit cylindrical roller thrust bearings with an outer diameter of $95 \mathrm{~mm}$ (type 81212) in order to compare their rolling contact fatigue behavior with that of industrial standard bearings. Using laser wire cladding, a hard layer out of martensitic chromium silicon steel (1.4718) was deposited on S235 (1.0038) steel base substrate. Subsequently, the bearing washers were forged. After finishing the surface, the bearing washers were prepared to be tested with the thrust bearings (Fig. 1) on a test rig. For the tests 19 rollers with a diameter of $11 \mathrm{~mm}$ and a length of $11 \mathrm{~mm}$ were mounted in a polyamide cage. Before and after each manufacturing step, the bearings were inspected by microscopic studies.

\section{Manufacturing process}

For the manufacturing of the axial bearing washers, the process chain depicted in Fig. 2 was set up. The process started with laser-cutting a disk as substrate, followed by laser-wire cladding the bearing washers at the Laser Zentrum Hannover e.V. (LZH). To enhance the coating, the washers were forged

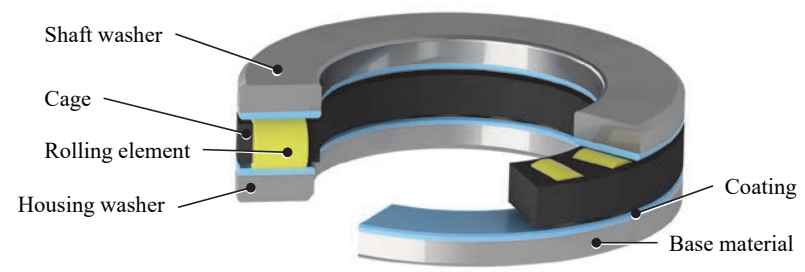

Fig. 1 Scheme of axial bearing with laser-cladded coating [11] at the Institute of Forming Technology and Machines (IFUM). After hard-turning the surface at the Institute of Machine Design and Tribology (IMKT) and a subsequent hardening process, the bearing washers were assembled with a industrial cage and rollers. In order to prove the feasibility of the concept, the bearings were tested in an FE8 test rig. After the test runs, surface and joining zone were characterized.

\subsection{Laser-wire cladding}

For manufacturing a hybrid part, two materials must be joined. The first step was to produce disks with a diameter of $\varnothing 110 \mathrm{~mm}$ and a concentric hole of $\varnothing 40 \mathrm{~mm}$ out of a $10 \mathrm{~mm}$ thick mild steel (S235 JR, (1.0038)) plate by laser cutting. Then the disks were sandblasted and cleaned with alcohol. For depositing the second material, a laser cladding process was utilized.

For cladding, a scanner-supported laser hot-wire process has been used. This involves a TRUMPF disk laser, a 1-D laser scanner and a DINSE hot-wire system as shown in Fig. 3. The process is explained in $[12,13]$. By means of laser cladding the welded layer is applied to a disk in form of a spiral using a rotational axis. The advantage of this cladding geometry is that the process does not have to be interrupted. However, the drawbacks are the constantly changing radius, which has to be compensated for, as well as an uncovered area in the first and last round as a result of the aforementioned change in radius.

For cladding, martensitic chrome silica steel (1.4718) was used in the form of a $\varnothing 0.8 \mathrm{~mm}$ wire. The material was chosen as it features a high hardness and is available as wire. A feed rate of $3.6 \mathrm{~m} / \mathrm{min}$ was used. For heating up the deposition material, electric resistance heating was applied with a current of $87 \mathrm{~A}$. The heated wire and the substrate material were fused together

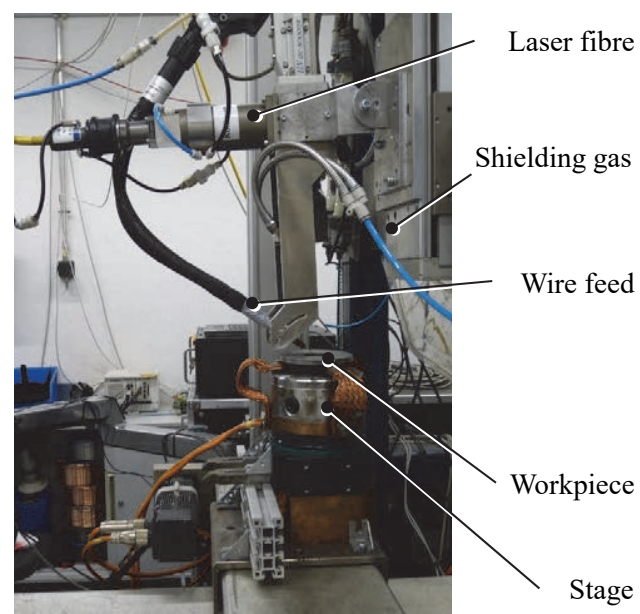

Fig. 3 Setup for hot-wire laser cladding

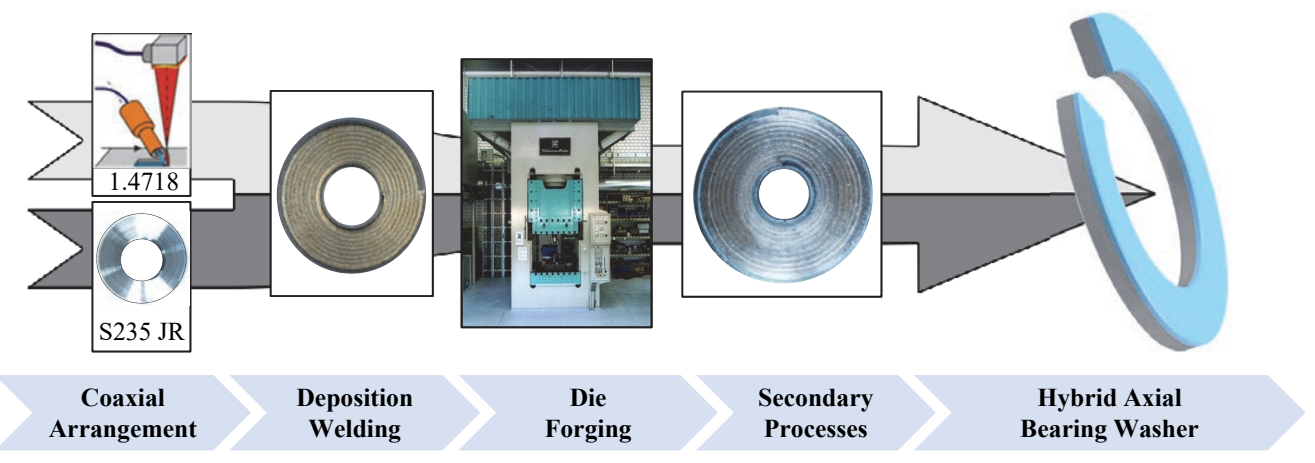

Fig. 2 Process chain for producing hybrid axial bearing washers [11] 
Florian Pape, Timm Coors, Alexander Barroi, Jörg Hermsdorf, Maximilian Mildebrath, Thomas Hassel, Stefan Kaierle, Tim Matthias, Alexander Chugreev, Anna Chugreeva, Bernd-Arno Behrens, Ludger Overmeyer and Gerhard Poll

by a $1800 \mathrm{~W}$ laser beam, which oscillated perpendicularly to the welding direction. This oscillation was realized by a onedimensional scanner and had the effect of changing the beam profile from a spot to a rectangle. A cross section of a coated steel disk with a total thickness of $10 \mathrm{~mm}$ is shown in Fig. 4.

\subsection{Forging}

The forming of the hybrid bearing washers was carried out after the laser welding process. The aim was to improve microstructure and mechanical properties of the welded material by means of thermal and mechanical treatment during the forming stage. In previous studies, the positive impact of forging after laser welding has already been demonstrated [14] By the subsequent forming of previously welded semi-finished workpieces, grain refinement can be achieved by combination of thermal and mechanical influences.

For the manufacturing of hybrid bearing washers, a singlestage forming process was developed whose tool system is depicted in Fig. 5(b). The forming experiments were performed on a hydraulic press with a maximum capacity of $12500 \mathrm{kN}$ (Fig. $5(a))$.
Before forging, the bearing washers were heated up to the forging temperature of $900^{\circ} \mathrm{C}$ in a chamber furnace. In order to determine the heating time, initial heating tests were conducted with thermocouples integrated in the specimens. After the heating stage, hybrid workpieces were manually transported to the forming tool and formed to the final geometry. The maximal pressing force of approx. $1700 \mathrm{kN}$ was measured by an integrated load cell. The height of the bearing washers was finally reduced to approx. $9 \mathrm{~mm}$. After forming, the forged bearing washers were slowly air-cooled. A cross section of the hybrid bearing washer after forging is shown in Fig. 6. The parts exhibited a good bonding quality between the two materials without any material separation or cracks.

\subsection{Hard-turning and finishing}

As a result of heating prior to the forming process, the hardness of the forged bearing washers was reduced compared to the hardness after laser cladding. To achieve a sufficient hardness of the bearing washers, a hardening process was performed before hard-turning. To achieve the final contour, the coated and forged disks were finished in a hard-turning process.

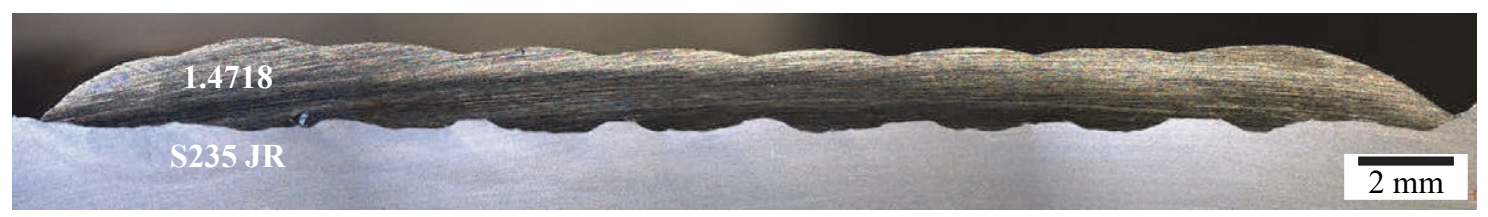

Fig. 4 Cross section of a coated steel disk [11]

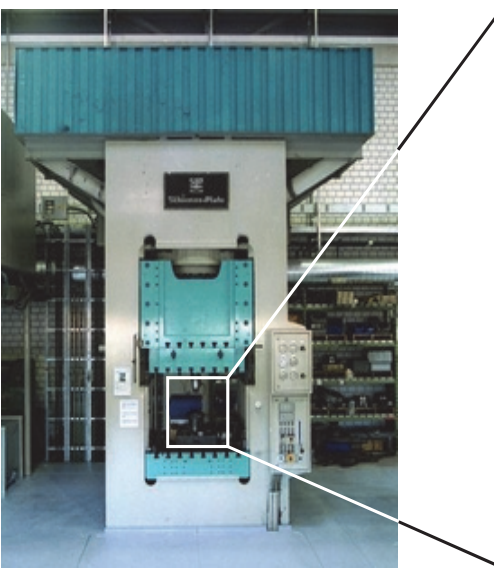

(a)

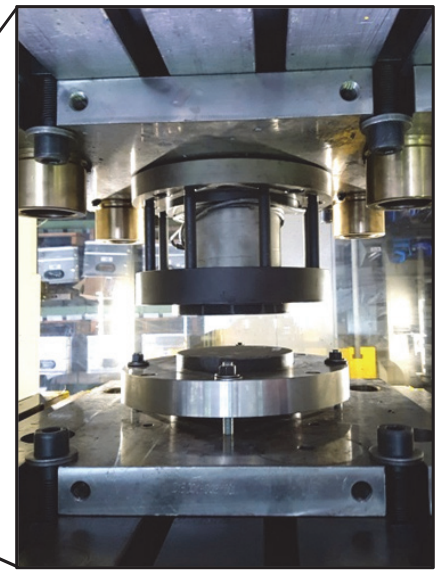

(b)

Fig. 5 (a) Hydraulic press and (b) forming tool system for the manufacturing of forged hybrid bearing washers [11]

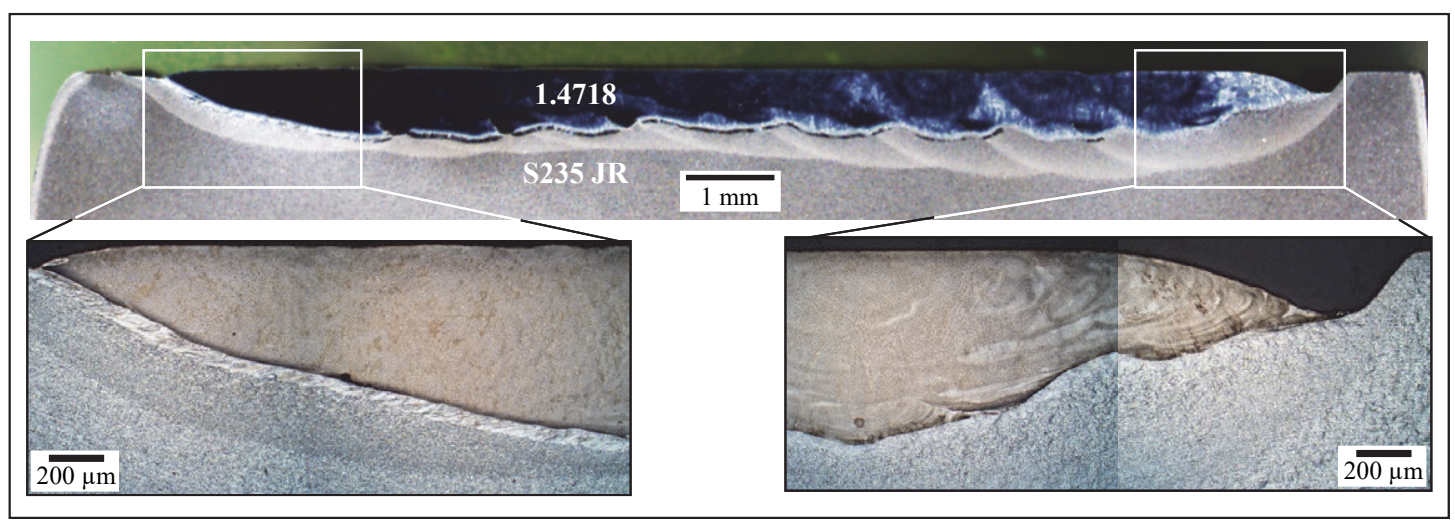

Fig. 6 Cross section of a hybrid bearing washer after forming [11] 
For these bearing washers, an outer diameter of $\varnothing 95 \mathrm{~mm}$ was chosen. For the inner hole a diameter of $\varnothing 60 \mathrm{~mm}$ for the type WS (allocated shaft washer), and an inner hole of $\varnothing 62 \mathrm{~mm}$ diameter for the type GS (allocated housing washer) were chosen. After the manufacturing process, roughness and surface profile were tactile measured using a Mahr Perthometer. A surface roughness of $R a=0.13 \mu \mathrm{m}$ was achieved after the hard-turning process.

\section{Bearing endurance tests}

The axial bearing washers were combined with rollers and a cage and tested in an FE-8 test rig (Fig. 7) typically used for the dynamic-mechanical measurement of rolling-element bearing lubricants [15]. This test is specified in the standard DIN 51819. For lubrication, OS-A oil was used at $70^{\circ} \mathrm{C}$, which is a highly refined mineral oil containing ZDDP additives. The pre-load of $40 \mathrm{kN}$ was applied to the bearings by means of disk springs. To stabilize the bearing temperature, the test head was ventilated. The parameters for the tests are shown in Table 1. A functional test was performed for $50 \mathrm{~h}$ and a second test was performed until bearing failure. This was determined by a condition

Table 1 Parameters for bearing tests

\begin{tabular}{l|c|c|c}
\hline FE-8 test parameters (2x 81212 TN bearings) \\
\hline Rotational speed & $n$ & 250 & $\mathrm{~min}^{-1}$ \\
\hline Axial load & $F_{\text {ax }}$ & 40 & $\mathrm{kN}$ \\
\hline Hertzian contact stress & $p_{\max }$ & 1.9 & $\mathrm{GPa}$ \\
\hline Viscosity at $40^{\circ} \mathrm{C}$ & $v_{40}$ & 90 & $\mathrm{~mm}^{2} / \mathrm{s}$ \\
\hline Oil temperature & $T_{\text {set }}$ & 70 & ${ }^{\circ} \mathrm{C}$ \\
\hline Viscosity ratio & $\kappa$ & 0.55 & \\
\hline
\end{tabular}

monitoring system, which is based on a vibration sensor. As reference, a pair of industrial bearings made from standard monolithic bearing steel were tested.

\section{Results}

The hardness measurements were performed on the TriboIndenter Hysitron TI950. The hardness was examined on the surface after each process step (Table 2). The nano hardness of the coating before the test run was 9 GPa and the Young's Modulus $200 \mathrm{GPa}$. This is comparable to the nano hardness of bearing steel as achieved in previous studies [16]. After bearing endurance tests the surface hardness of the bearing washers is reduced. This can be explained by boundary layers originated on the bearings surface.

In a first step, a functional test of the bearings was executed with a Hertzian contact pressure of $\mathrm{p}_{\mathrm{H}}=2300 \mathrm{MPa}$ for $50 \mathrm{~h}$. Under testing conditions, the surface only shows slight traces on the raceways (Fig. 8(a)). After testing, the bearing washers were

Table 2 Hardness of the bearing washers after each manufacturing step

\begin{tabular}{l|l}
\hline Hardness: & Nano hardness \\
\hline Industrial bearing 100Cr6 & $11 \mathrm{GPa}$ \\
\hline Coating after hard-facing & $7 \mathrm{GPa}$ \\
\hline Coating after forging & $6 \mathrm{GPa}$ \\
\hline Coating after hardening & $9 \mathrm{GPa}$ \\
\hline Coating after run-in & $9 \mathrm{GPa}$ \\
\hline Coating after endurance test & $7 \mathrm{GPa}$ \\
\hline
\end{tabular}
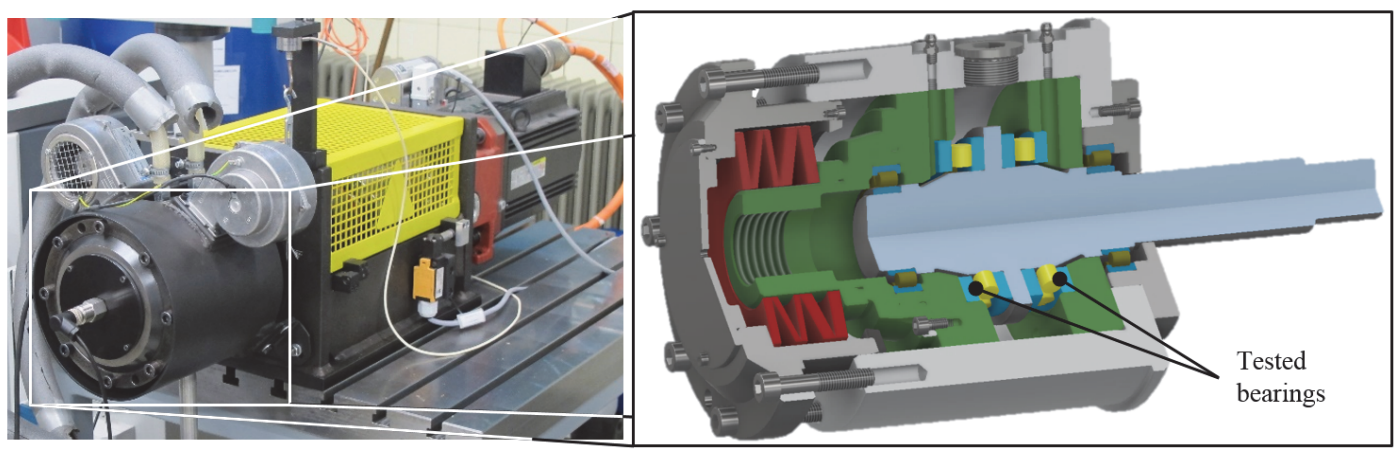

Fig. 7 FE-8 test rig for the dynamic-mechanical measurement of rolling element bearings

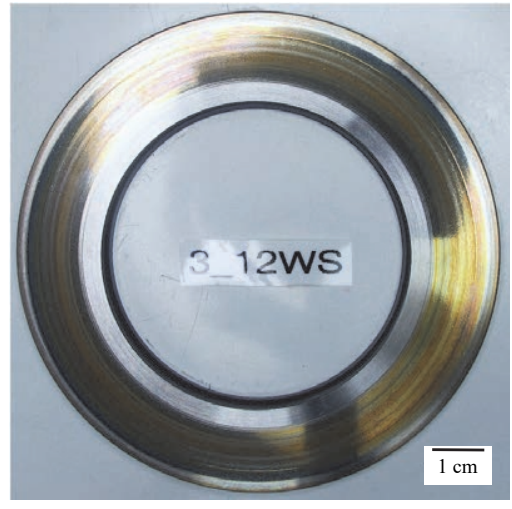

(a)

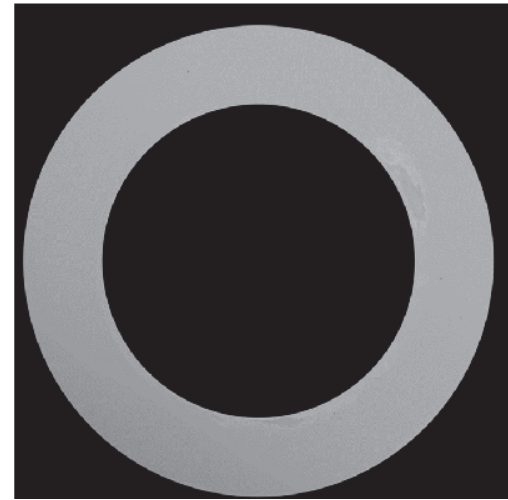

(b)

Fig. $850 \mathrm{~h}$ functional test: (a) photograph of bearing washer, (b) ultrasonic micrograph 
Florian Pape, Timm Coors, Alexander Barroi, Jörg Hermsdorf, Maximilian Mildebrath, Thomas Hassel, Stefan Kaierle, Tim Matthias, Alexander Chugreev, Anna Chugreeva, Bernd-Arno Behrens, Ludger Overmeyer and Gerhard Poll

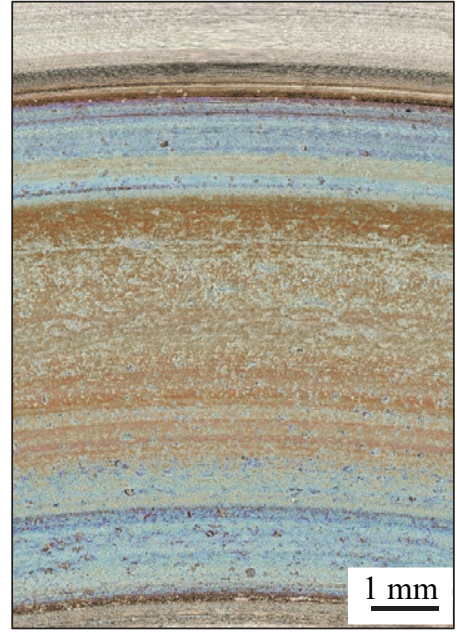

(a)

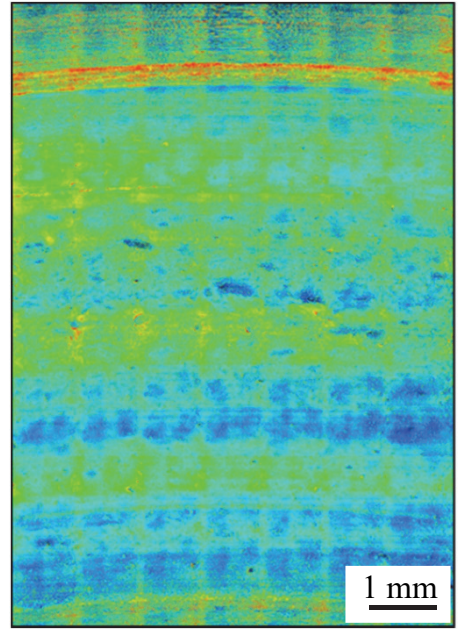

(b)

Fig. 9 Detail view of bearing washer surface after FE8 test (50 h under $40 \mathrm{kN}$ ): (a) optical micrograph, (b) laser scanning image

analyzed with laser scanning microscopy. The surface is shown in detail in Fig. 9. On the raceway, a tribofilm is formed. The tribofilm formation is caused due to tribochemical reactions of the ZDDP additives on the surface [17]. No pittings due to material fatigue or other wear marks can be found. In addition, ultrasonic scans were performed proving surface reliability (Fig. 8(b)). The method allows for a tomographic representation of material defects in multi-material components. For the test, the washer was placed in a water bath acting as coupling medium. Short ultrasonic pulses are produced and received by a transducer/receiver unit as the centerpiece of the ultrasonic microscope. The ultrasonic pulse reflection is influenced by subsurface cracks, inclusions, and pores. In case of the bearing washers it is possible to evaluate the joining zone regarding defects and pores. The resolution is in the scale of a few microns. After the successful functional test, a fatigue life test was performed.

A second set of rolling element bearings was used for a fatigue life test. In this case, the bearing ran for $260 \mathrm{~h}$ until failure due to significant pittings on the rollers and pittings on the bearing surface. The damage caused to the rollers is depicted in Fig. 10; the bearing surface is shown in Fig. 11(a). Additional ultrasonic scans proved the integrity of the joining zone (Fig. 11(b)). On the surface, pittings with a depth of up to

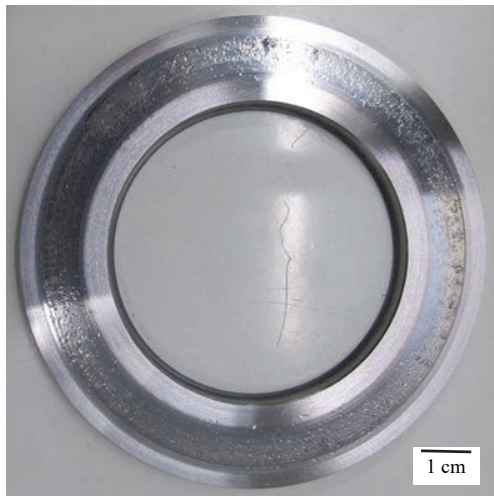

(a)
$135 \mu \mathrm{m}$ could be detected by laser scanning microscopy (Fig. 12). The fatigue test was successfully passed proving that the coat did not show any delaminations.

As reference, the fatigue life of the hybrid bearings was compared to standard industrial bearings made from monolithic bearing steel 100Cr6 (1.3505) (shown in Fig. 13). The roughness of the industrial bearings is lower than $R a=0.06 \mu \mathrm{m}$. Due to the advantageous material and workpiece properties (higher hardness, higher fatigue limit, reduced roughness), the reference component achieved a higher fatigue life of $390 \mathrm{~h}$. A damage with a depth of $12 \mu \mathrm{m}$ led to the test bench being shut down due to vibrational measurements (Fig. 14).

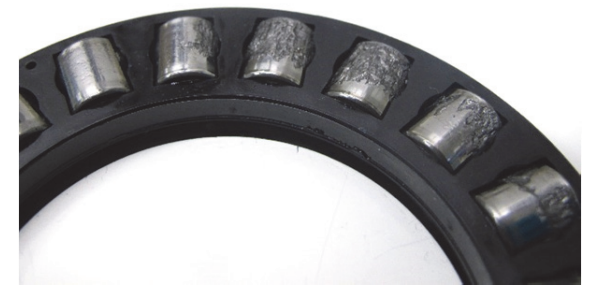

Fig. 10 Significant pittings on the bearing rollers after endurance test $(260 \mathrm{~h})$

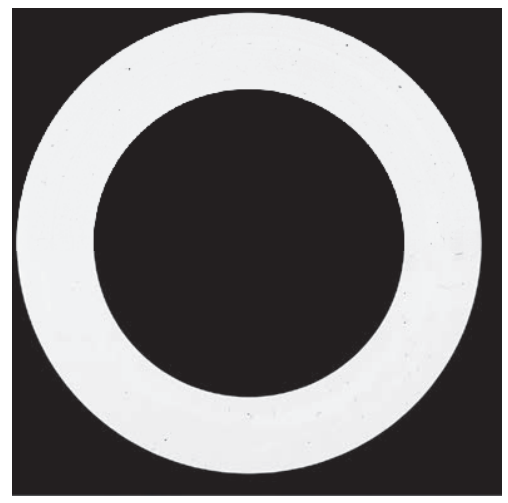

(b)

Fig. $11260 \mathrm{~h}$ functional test: (a) photograph of bearing washer (GS), (b) ultrasonic (WS) 


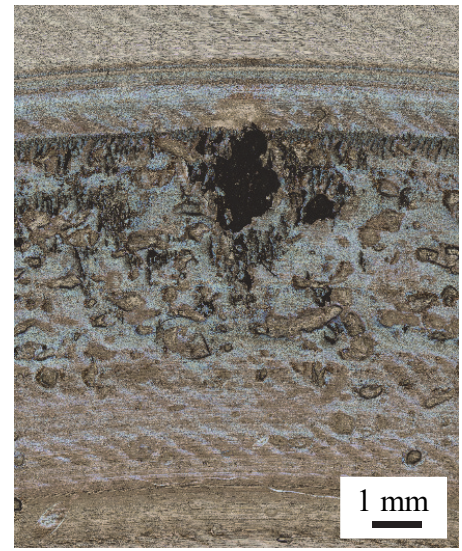

(a)

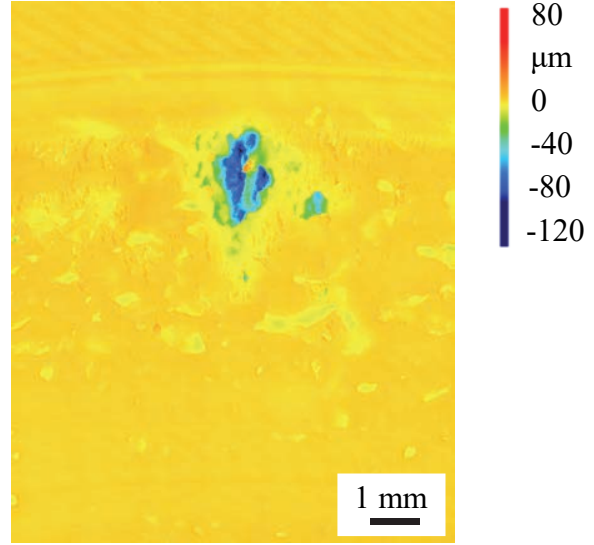

(b)

Fig. 12 Detail of bearing washer surface after FE8 test ( $260 \mathrm{~h}$ under $40 \mathrm{kN}$ : (a) micrograph, (b) laser scanning image

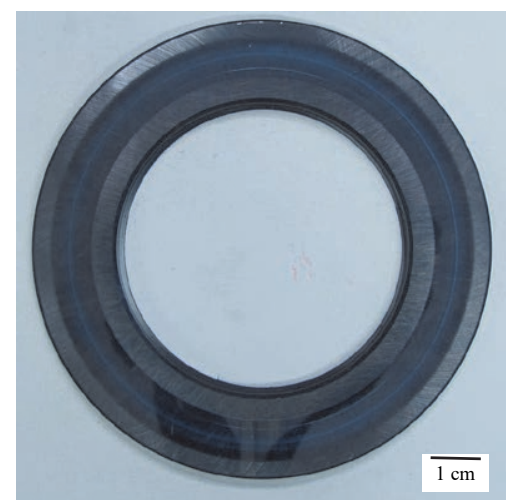

(a)

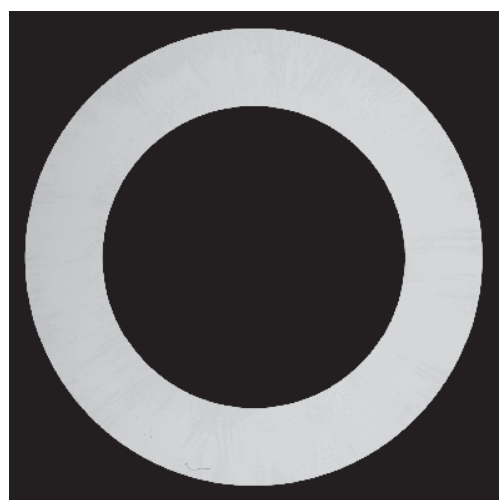

(b)

Fig. 13 Industrial reference bearing washer after $390 \mathrm{~h}$ testing: (a) photograph with damage at 12 o' clock position, b) ultrasonic micrograph

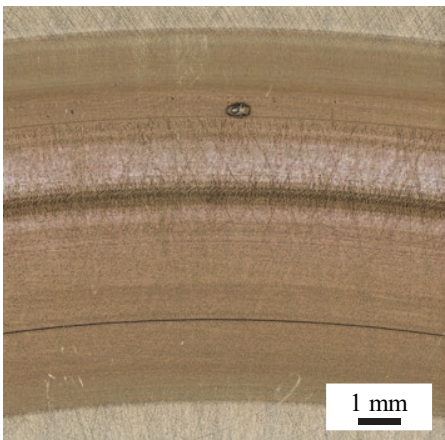

(a)

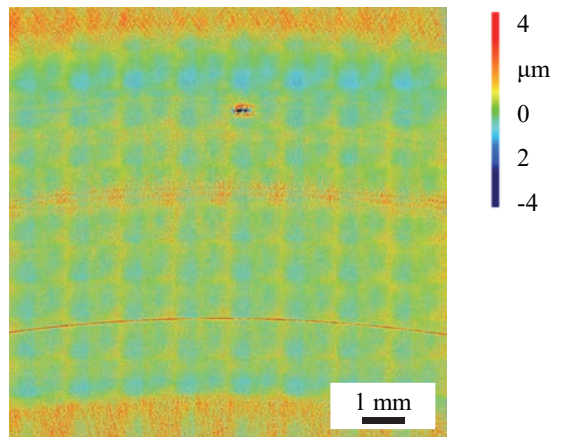

(b)

Fig. 14 Detail view of reference bearing washer surface after FE8 test (390 h under $40 \mathrm{kN}$ ): (a) micrograph, (b) laser scanning image

\section{Conclusion}

To summarize, the manufacturing of tailored-formed bearing washers by laser-wire cladding with subsequent forging is implemented in this work. The coatings are free of impurities, homogeneous and feature a good bonding to the base material. Compared to bearing steel the hardness on the raceway is lowered by $20 \%$. A functional test was successfully passed. An endurance test showed that the bearing failed due to pittings. The joining zone could withstand the stress. While the axial bearing washers feature different slip to roll ratios in tribological contact, the coating could withstand the additionally induced tangential stresses. Compared to an industrial bearing the tailored forming bearing reached nearly $70 \%$ of the running time until failure. The increased bearing fatigue life can be attributed to the higher hardness and higher fatigue limit of the bearing steel. To achieve an increased statistic of this comparison more tests will have to be conducted. The tailored forming technology demonstrates a high potential for parts commonly used in mechanical engineering. Combining the individual benefits of several materials in a single component, this concept offers the production of application-optimized 
Florian Pape, Timm Coors, Alexander Barroi, Jörg Hermsdorf, Maximilian Mildebrath, Thomas Hassel, Stefan Kaierle, Tim Matthias, Alexander Chugreev, Anna Chugreeva, Bernd-Arno Behrens, Ludger Overmeyer and Gerhard Poll
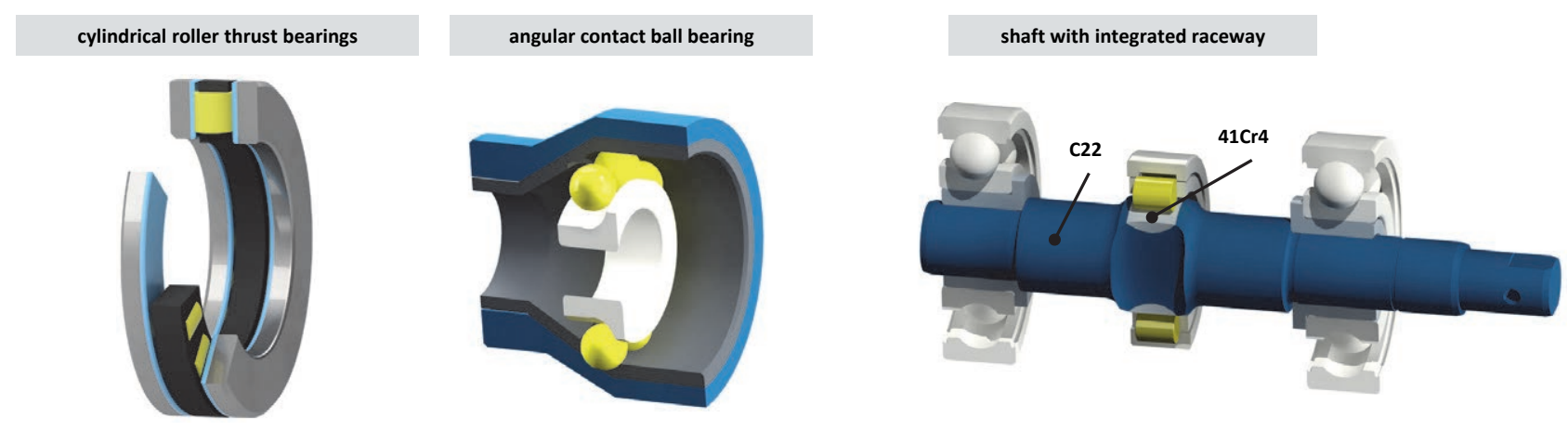

Fig. 15 Hybrid bearing types

parts with a high performance. Such components can be more cost-efficient and resource-saving due to locally adapted material characteristics. In future works, the approach will be expanded to radial bearings and angular contact ball bearings (Fig. 15). The knowledge gained by means of this process chain will be transferred to these bearings as well. There is also high potential of this approach regarding bearings for wind turbines as well as the automotive sector.

\section{Acknowledgement}

The results presented in this paper were obtained within the Collaborative Research Centre 1153 "Process chain to produce hybrid high performance components by Tailored Forming" in the subprojects A4, B2, C1 and C3. The authors would like to thank the German Research Foundation (DFG) for the financial and organizational support of the project.

\section{References}

[1] Politis, D. J., Lin, J. and Dean, T., "Investigation of Material Flow in Forging Bi-Metal Components," Steel Research International: Special Edition, 14, 2012, 231-234.

[2] Kong, T. F., Chan, L. C. and Lee, T. C., "Experimental Study of Effects of Process Parameters in Forge-Welding Bimetallic Materials: AISI 316L Stainless Steel and 6063 Aluminium Alloy," Strain, 45, 4, 2009, 373-379.

[3] Hetzner, D. W., "Laser Glazed Bearings," Bearing Steels: Into the 21st Century, Issue 1327, J. Hoo and W. Green (eds.), American Society for Testing and Materials., ASTM International, 1998, 471495.

[4] Enomoto, Y. and Yamamoto, T., "New Materials in Automotive Tribology," Tribology Letters, 5, 1, 1998, 13-24.

[5] Torims, T., "The Application of Laser Cladding to Mechanical Component Repair, Renovation and Regeneration," Chapter 32, DAAAM International Scientific Book 2013, B. Katalinic and Z. Tekic (eds.), Vienna, Austria, 2013, 587-608.

[6] Pape, F., Nölke, C., Kaierle, S., Hangen, U. D., Reiter, R. and Wesling, V., "Tribological Investigation of Laser Cladded Ceramic A12O3 Coatings on Aluminium," Proc. 5th World Tribology Congress, Torino, Italy, 2013.

[7] Weisheit, A., Gasser, A., Backes, G., Jambor, T., Pirch, N. and Wissenbach, K., "Direct Laser Cladding, Current Status and Future Scope of Application," Laser-Assisted Fabrication of Materials,
Majumdar, J. and Manna, I. (eds.), Springer Series in Materials Science, 161, Springer, Berlin, Heidelberg, 2013, 221-240.

[8] Behrens, B.-A., Bouguecha, A., Frischkorn, C., Huskic, A., Stakhieva, A. and Duran, D., "Tailored Forming Technology for Three Dimensional Components: Approaches to Heating and Forming," Proc. 5th International Conference on Thermomechanical Processing TMP 2016, Milan, Italy, 2016.

[9] Coors, T., Pape, F. and Poll, G., "Concept for Enhancing Machine Elements by Residual Stresses and Tailored Forming," Proc. IAMOT 2017, Vienna, Austria, 2017.

[10] Behrens, B.-A., Bouguecha, A., Bonk, C. and Matthias, T., "Importance of Material and Friction Characterisation for FE-Aided Process Design of Hybrid Bevel Gears," Proc. ESAFORM, Dublin, Ireland, 2017.

[11] Pape, F., Coors, T., Barroi, A., Hermsdorf, J., Mildebrath, M., Hassel, T., Kaierle, S., Matthias, T., Bonk, C., Chugreeva, A., Bonhage, M., Bouguecha, A., Behrens, B.-A., Overmeyer, L. and Poll, G., "Tribological Investigations on Tailored Formed Axial Bearing Washers," Proc. 6th World Tribology Congress, Beijing, China, 2017.

[12] Barroi, A., Gonçalves, D. A., Hermsdorf, J., Kaierle, S. and Overmeyer, L., "Influence of Laser Power on the Shape of Single Tracks in Scanner Based Laser Wire Cladding," Physics Procedia, 83, 2016, 667-673.

[13] Barroi, A., Hermsdorf, J., Kaierle, S. and Overmeyer, L., "Influence of Scan Width and Wire Feed Speed on Seam Geometry and the Substrate Surface in Laser Wire Cladding," Proc. ICALEO 2016, San Diego, USA, 2016.

[14] Behrens, B.-A., Overmeyer, L., Barroi, A., Frischkorn, C., Hermsdorf, J., Kaierle, S., Stonis, M. and Huskic, A., "Basic Study on the Process Combination of Deposition Welding and Subsequent Hot Bulk Forming," Production Engineering - Research and Development, 7, 6, 2013, 585-591.

[15] DIN 51819: Mechanisch-Dynamische Prüfung auf dem Wälzlagerschmierstoff-Prüfgerät FE8 - Teil 3: Verfahren für Schmieröl, einzusetzende Prüflager, Axialzylinderrollenlager, 2005 (in German).

[16] Pape, F., “Mikrotribologische Untersuchungen an Wälzlagern mit polymeradditiver Fettschmierung, Thesis, Berichte aus dem impt, Tewiss, 2011, 125 (in German).

[17] Pape, F., Möbes, G., Lipinsky, D., Muhmann, C., Arlinghaus, H. F. and Poll, G., "Investigation of the Temperature Influence on the Formation of Boundary Layers on Bearings," Tribologie und Schmierungstechnik, 64, 2017, 39-46. 